(2) Open Access Full Text Article

\title{
Intensive Care Nurses' Knowledge, Attitude, and Practice of Pressure Injury Prevention in China: A Cross-Sectional Study
}

\author{
Li Hu ${ }^{1,2}$ \\ Wipa Sae-Sia ${ }^{2}$ \\ Luppana Kitrungrote (iD) ${ }^{2}$ \\ 'Breast Surgery Department, The \\ Affiliated Hospital of Guizhou Medical \\ University, Guiyang, Guizhou, People's \\ Republic of China; ${ }^{2}$ Faculty of Nursing, \\ Prince of Songkla University, Hatyai, \\ Songkhla, Thailand
}

Background: Pressure injury (PI) remains a critical health issue worldwide. The global incidence of hospital-acquired PI is $8.4 \%$, and among intensive-care unit (ICU) patients, it is even higher, ranging from $6.60 \%$ to $36.80 \%$. It is important to investigate ICU nurses' PI prevention knowledge, attitudes, and practices (KAP).

Aim: The aim of this study was to describe the level of Chinese ICU nurses' knowledge, attitudes, and self-reported practices of PI prevention.

Materials and Methods: From March 31 to April 30, 2019, we recruited a total of 510 ICU nurses into the current study using convenience sampling. The Modified Pressure Ulcer Knowledge Assessment Tool version 2.0, Attitudes toward Pressure Ulcer Prevention instrument, and Questionnaire to evaluate nurses' Adherence to Recommendations for Preventing Pressure Ulcers were used for data collection. We used one-way analysis of variance, Student's $t$-test, and the Mann-Whitney $U$-test to assess differences in knowledge, attitudes, and self-reported practices of PI prevention among ICU nurses, whom we categorized by their demographic characteristics.

Results: Mean scores of participants' knowledge, attitude, and their self-report practice were $65.82 \pm 9.29,76.65 \pm 8.62$, and $83.35 \pm 13.55$, respectively. Participants with bachelor's degrees or higher, who worked in tertiary hospitals, and who had received training on PI prevention over the last year had higher scored on PI prevention knowledge (all $P<0.05$ ). Participants who had received training on PI prevention over the last year scored higher on attitude than those who had not received such training over the last year $(P=0.001)$.

Conclusion: ICU nurses surveyed in this study did not demonstrate an acceptable level of knowledge about PI prevention, while their attitudes and self-reported practices were acceptable. Continuing education or in-service training should be provided to enhance ICU nurses' knowledge of PI prevention.

Keywords: intensive-care unit nurse, knowledge, attitude, practice, pressure injury prevention

\section{Introduction}

A pressure injury (PI) is the localized damage caused by persistent pressure or pressure combined with shear, which usually presents on the skin and/or tissue over a bony prominence or under medical or other devices. ${ }^{1}$ Most PIs are preventable, and the National Quality Forum has added the development of hospital-acquired PI to its list of "Never Events." 2 However, despite the international guidelines on PI prevention that have been issued, ${ }^{3,4}$ the incidence of PI is still of concern worldwide, regardless of national income level. A recent systematic review showed that 
the global incidence of hospital-acquired PI is $8.4 \%{ }^{5}$ Another study showed that PI incidence among intensivecare unit (ICU) patients is even higher, ranging from $6.60 \%$ to $36.80 \%$ globally. ${ }^{6}$ In Europe, PI incidence among ICU patients is $8.10-31 \% .^{7-9}$ Studies of Middle Eastern countries have shown that $8.90 \%$ of ICU patients developed PI during ICU stays in Iran, ${ }^{10}$ followed by $17 \%$ in Turkey, ${ }^{11} 33.70 \%$ in Lebanon, ${ }^{12}$ and $39.30 \%$ in Saudi Arabia. ${ }^{13}$ Within China, ICU patients have the highest PI incidence, $4.48 \%$, much higher than the overall PI incidence of $0.63 \%{ }^{14}$

PI is a painful and costly medical condition that can prolong hospital stay, increase the cost of treatment, and even cause death. Patients with PIs stay longer in the hospital than patients without PIs, ${ }^{15,16}$ and their treatment costs are also significantly higher. ${ }^{16}$ According to Padula et al, the average cost of a hospital-acquired PI was $\$ 10,708$, indicating the $\$ 26.80$ billion cost of PI care in the US based on 2.50 reported cases each year. ${ }^{17}$ In addition, PIs can increase risk of infection. Guest et al reported that up to $53 \%$ of PIs have become clinically infected. ${ }^{18}$ Infected PIs can result in cellulitis, abscess, osteomyelitis, and bacteremia, all of which can lead to significant mortality. ${ }^{19}$ The mortality rate is significantly higher in patients with PIs than patients without $(9.10 \%$ vs $1.80 \%) .{ }^{16}$ Moreover, a nurse's workload increases by $50 \%$ with the development of a PI. ${ }^{20}$ Strategies that include risk identification, skin assessment, skin care, patient repositioning, and pressure-reducing devices can be applied to prevent PIs. ${ }^{3,4}$ Because of the tremendous medical and financial burdens that PIs place on patients, ${ }^{15-20}$ efforts should be focused on their prevention.

The knowledge-attitude-practice (KAP) model postulates that knowledge, attitude, and practice in healthcare workers are mutually related and that knowledge and attitude directly affect preventive practice. ${ }^{21}$ In China, the nurse is the clinician who screens patients at risk of PIs using a risk assessment tool and who provides preventive interventions for those at risk. Therefore, nurses' PI prevention KAP directly affects the quality of nursing care and patient outcomes, and studies seeking to understand nurses' PI prevention KAP should be conducted regularly to promote such prevention. ${ }^{3}$ Several such studies have already been conducted, but their findings have been inconsistent. Some report that nurses' knowledge, ${ }^{22,23}$ attitudes, ${ }^{24}$ and practice ${ }^{25}$ are at acceptable levels, while some report otherwise. ${ }^{20,26,27}$ In addition, studies remain scarce on ICU nurses' KAP of PI prevention. Khojastehfar et al investigated Iranian ICU nurses' KAP in this arena and found that while their knowledge and attitudes were undesirable, their practices thereof were desirable. ${ }^{25}$ In Nepal, Shrestha et al demonstrated that ICU nurses' PI prevention knowledge and practices were at low levels, while their attitude toward PI prevention was at a moderate level. ${ }^{28}$

To the best of our knowledge, ICU nurses' KAP of PI prevention has not been elucidated in China. ${ }^{29-31}$ An assessment of the same is critically needed among ICU nurses specifically, considering that PIs are most prevalent in the ICU setting and have detrimental effects on patients. Therefore, the present study examined this topic with the aim of providing nursing administrators with baseline data with which to develop training programs to increase ICU nurses' PI prevention KAP, thereby improving the quality of PI prevention.

The basic question asked in this study was, "What is the level of Chinese ICU nurses' knowledge, attitudes, and practice of PI prevention?" Nurses' knowledge of PI prevention included basic recall and understanding of the content of PI etiology, classification and observation, risk assessment, preventive measures, preventive nutrition, and prevention in special patient groups (ie, critically ill patients). Their attitudes toward PI prevention were defined as their preconceived beliefs about their personal competence at preventing PIs, how they prioritized PI prevention, their recognition of the impact of PIs and their personal responsibility in preventing them, and their confidence in the effectiveness of PI prevention. Nurses' practices of PI prevention included their performance of PI preventive measures, including use of risk-predictive instruments; evaluation, skin care, and selection of special surfaces for pressure management; postural change; force and pressure relief; and nutrition for PI prevention.

\section{Materials and Methods Study Design}

We conducted a web-based, cross-sectional descriptive study from March 31 to April 30, 2019.

\section{Sample and Setting}

This study was conducted in the ICUs of 25 secondary and 29 tertiary hospitals in Guizhou Province, China. In China, secondary hospitals are regional hospitals that are responsible for providing comprehensive health services, as well as delivering medical education and conducting research on a regional basis. They generally contain 101-499 beds. 
Tertiary hospitals are comprehensive referral hospitals that provide specialist health services and play a larger role in medical education and research; they generally contain $>500$ beds.

The target population of this study was ICU nurses working in adult ICUs across Guizhou Province. We adopted a convenience sampling method to recruit participants. Initially, we contacted the head ICU nurses at the hospitals in question and asked whether they would help us carry out the study; if they were willing, we subsequently enrolled the ICU nurses at their hospitals in our study. Inclusion criteria were as follows: registered nurses who were (1) engaged in clinical work in adult ICUs across Guizhou province and (2) willing to participate in the study. Exclusion criteria were as follows: nurses who were (1) rotating in the ICU; (2) training in the ICU; or (3) absent from work due to sick, personal, or maternity leave for the duration of the survey. Sample size was calculated based on the Yamane formula $\mathrm{N} / 1+\mathrm{N}^{*} \mathrm{e}^{2} \cdot{ }^{32}$ According to data collected by the Nursing Quality Control Center of Guizhou Province, in 2019 the total population of adult ICU nurses in that province was 2586, setting the confidence interval (CI) at 95\%; therefore, we set a minimal sample size of 347 participants. Noting that a previous online survey had a non-response rate of $45.5 \%,{ }^{33}$ we increased our sample size by $50 \%$, extending it to 520 participants. Ultimately, a total of 510 ICU nurses completed the online survey.

\section{Instrument}

We modified the Pressure Ulcer Knowledge Assessment Tool version 2.0 (PUKAT 2.0), which was developed and verified by Manderlier et al, ${ }^{34}$ into a questionnaire with which to measure participants' PI prevention knowledge. Items 3, 16, and 20 of the original questionnaire were deleted as these items are not appropriate to Chinese settings. Items 24 and 25 of the original questionnaire were modified to be specific to ICU settings. The final modified questionnaire had 22 items to be answered with "true," "false," or "do not know," covering six themes of PI prevention knowledge: (1) etiology, (2) classification and observation, (3) risk assessment, (4) nutrition, (5) PI prevention, and (6) specific patient group. The final score ranged from 0 to 22; a correct answer was scored 1 point, while a wrong or "do not know" answer was scored 0 points. There is no recommended cutoff score for the original questionnaire. ${ }^{34}$ In this study, we translated total scores into percentage scores and set mean cutoff score at
$80 / 100$ to reflect sufficient knowledge of PI prevention on the part of the ICU nurse, in accordance with a similar study conducted among Chinese general nurses. ${ }^{31}$

Participants' PI prevention attitude was measured by the Attitude toward Pressure Ulcer Prevention Instrument (APuP), developed and validated by Beeckman et al. ${ }^{35}$ The instrument consists of 13 items covering five themes: (1) personal competency to prevent PIs, (2) prioritizing PI prevention, (3) the impact of PIs, (4) personal responsibility in PI prevention, and (5) confidence in the effectiveness of PI prevention. Each item is rated on a four-level Likert scale ( 1 = strongly disagree, 2 = disagree, 3 = agree, $4=$ strongly agree). Negatively narrative items are reverse scored (items 3, 4, 5, 7, 8, 10, and 13). Total score ranges from 13 to 52; higher scores indicate more-positive attitudes toward PI prevention. We translated these scores into percentage scores and categorized them into two levels: $\geq 75$ indicated satisfactory attitudes, while $<75$ indicated unsatisfactory attitudes. ${ }^{35}$ Feng et al have translated the APuP into Chinese and used it to measure nurses' attitudes toward PI prevention; in their study, Cronbach's $\alpha$ for the APuP was $0.73 .^{29}$

Participants' PI prevention practices were measured by the Questionnaire to evaluate nurses' Adherence to Recommendations for Preventing Pressure Ulcers (QARPPU), developed and verified by Moya-Suarez et al. ${ }^{33}$ This questionnaire has been modified for better specificity and suitability to Chinese critical-care settings. The modified QARPPU is a 17-item questionnaire covering five themes: (1) use of a risk-predictive instrument; (2) evaluation, skin care, and selection of special surfaces; (3) postural change; (4) force and pressure relief; and (5) nutrition for PI prevention. Each item is rated on a five-point Likert scale (1 = never, 2 = rarely, $3=$ sometimes, $4=$ often, $5=$ always $)$. Total score ranges from 17 to 85 . Moya-Suarez et al did not determine a cutoff score for good practice of PI prevention. Again, we translated total scores into percentage scores, and for this questionnaire we selected a mean cutoff score of 80 to reflect the nurse's good performance on PI prevention practice, based on a previous study in China. ${ }^{31}$

The data collection instrument had four parts: demographic information, and then three questionnaires that measured PI prevention knowledge, PI prevention attitude, and PI prevention practice. We collected participants' demographic information using a researcher-developed questionnaire that covered age, gender, highest educational level, types of hospitals worked in, years of work in ICUs, 
training experience on PI prevention over the last year, and need for training on PI prevention.

Before collecting data, we obtained permission to use, translate, and modify the PUKAT 2.0, APuP, and QARPPU from their respective authors, as well as permission to use the Chinese version of APuP from the relevant Chinese scholars. Both the PI prevention knowledge and PI prevention practice questionnaires were translated into Chinese following the back-translation technique. ${ }^{36}$ First, a researcher translated the questionnaires into Chinese. Next, a nursing lecturer back-translated them into English. Finally, a Chinese registered nurse with a master's degree in nursing from Ireland compared the two versions of the English-language questionnaire to determine their equivalence. Two university lecturers who are experts in wound care, and one wound care expert from the Wound, Ostomy, and Incontinence Nursing Professional Committee of the Chinese Nursing Association, were invited to verify the contents of the PI prevention knowledge, attitude, and practice questionnaires, yielding Scaled Content Validity Index (S-CVI) values of $0.97,0.92$, and 0.98 , respectively. Furthermore, we tested these questionnaires for reliability among 20 ICU nurses. The intraclass correlation coefficient (ICC) for the PI prevention knowledge questionnaire was 0.72 , and proportions of agreement of its six themes were as follows: etiology, 0.70; classification and observation, 0.65 ; risk assessment, 0.60 ; nutrition, 0.70 ; PI prevention, 0.55 ; and specific patient group, 0.95. Cronbach's $\alpha$ values were 0.70 and 0.85 for the attitude and practice questionnaires, respectively.

\section{Data Collection Procedure}

We collected data from March 31 to April 30, 2019 using Wen Juan Xing, a professional online questionnaire survey, examination, evaluation, and voting platform that has been widely used in China for research and examinations. First, we identified a list of hospitals with established ICUs. Second, we contacted the head nurses in those ICUs and asked for their help in recruiting participants. Third, to the head nurses who agreed to participate, we explained the study's purpose and its inclusion and exclusion criteria. Finally, we emailed those head nurses a hyperlink to the online questionnaire, with an attached consent page explaining the purpose of the study and the principles of anonymity, confidentiality, and voluntary participation. They subsequently forwarded the email to eligible nurses in their
ICUs and instructed them to complete and submit the online survey. In all, 510 nurses submitted the completed survey.

\section{Ethical Acknowledgment}

Study procedures were reviewed and approved by the Center for Social and Behavioral Sciences Institutional Review Board, Prince of Songkla University, Hat Yai, Thailand (No. 2020 Nst-Qn 001); and Guizhou Medical University, Guiyang, China (No. 2019-162). Participation in this study was completely voluntary, and all data were kept confidential and anonymous. Before participating in this study, all participants completed the electronic informed consent form.

\section{Data Analysis}

We used descriptive statistics to describe participants' demographic characteristics and their levels of PI prevention KAP. Before conducting inferential statistics, we checked assumptions of normality and homogeneity of variance $(\mathrm{HoV})$ for PI prevention KAP scores categorized by participants' demographic characteristics. According to $\mathrm{Kim},{ }^{37}$ for a study with a sample size of $>300$ participants, if absolute skewness is $<2$ or absolute kurtosis is $<7$, the data are normal. For our data, all absolute-skewness values were $<2$ and all kurtosis values $<7$. The data were distributed normally. Using Levene's test, we checked the assumption of HoV for PI prevention KAP scores categorized by participants' demographic characteristics; we found that the assumption was met except for the characteristic of PI prevention knowledge categorized by training experience over the last year. Therefore, we used one-way analysis of variance (ANOVA) to test differences in PI prevention KAP scores by participants' ages and working years in ICUs, while Student's $t$-test and the MannWhitney $U$-test were used to test differences in PI prevention KAP scores by participants' genders, highest educational levels, types of hospitals worked in, training experience in PI prevention over the last year, and need for training on PI prevention. We used the $U$-test only to detect differences in knowledge between nurses who received training on PI prevention over last year and those who did not, because the assumption of HoV was not met. Significance was set at $P<0.05$. We analyzed all data using SPSS software version 23 (IBM Corp, Armonk, NY, USA). 


\section{Results}

\section{Demographic Information of Participants}

In this study, 25 tertiary hospitals and 29 secondary hospitals agreed to participate in the study. A total of 1258 ICU nurses were eligible to fill out the questionnaire; 510 of them completed it, yielding a response rate of $40.54 \%$. Demographic characteristics are presented in Table 1. Mean participant age was $30.42 \pm 5.32$ years. The majority were female $(n=433$, $84.9 \%)$, had a bachelor's degree $(\mathrm{n}=364,71.4 \%)$, and worked in tertiary hospitals $(\mathrm{n}=334,65.5 \%) ; 50.8 \%$ of participants had worked in ICUs for $>5$ years. Most participants reported that they had received training on PI prevention over the last year $(\mathrm{n}=341,66.9 \%)$, and that they required further training on this topic $(n=486,95.3 \%)$.

\section{Pressure Injury Prevention Knowledge}

Mean score of PI prevention knowledge was $65.82 \pm 9.29$. The lowest score was on the theme of "etiology," with an average score of $50.90 \pm 15.26$, followed by those of "risk assessment" (58.82 \pm 32.12$)$, “nutrition for PI prevention" (61.11 \pm 20.41$)$,

Table I Demographic Information of Participants

\begin{tabular}{|c|c|c|}
\hline Variables & $\mathbf{n}$ & $\%$ \\
\hline \multirow{2}{*}{\multicolumn{3}{|c|}{$\begin{array}{l}\text { Age (years) } \\
(M=30.42, S D=5.32, \operatorname{Min}-M a x=21-50)\end{array}$}} \\
\hline & & \\
\hline $21-30$ & 280 & 54.9 \\
\hline $31-40$ & 209 & 41.0 \\
\hline $4 \mid-50$ & 21 & 4.1 \\
\hline \multicolumn{3}{|l|}{ Gender } \\
\hline Female & 433 & 84.9 \\
\hline Male & 77 & 15.1 \\
\hline \multicolumn{3}{|l|}{ Highest Education Level } \\
\hline Junior college & 146 & 28.6 \\
\hline Bachelor and above & 364 & 71.4 \\
\hline \multicolumn{3}{|l|}{ Type of Hospital } \\
\hline Secondary & 176 & 34.5 \\
\hline Tertiary & 334 & 65.5 \\
\hline \multicolumn{3}{|l|}{ Working years in ICU } \\
\hline$<5$ & 251 & 49.2 \\
\hline $5-10$ & 187 & 36.7 \\
\hline$>10$ & 72 & 14.1 \\
\hline \multicolumn{3}{|l|}{ Received training on PI prevention over the last year } \\
\hline Yes & 341 & 66.9 \\
\hline No & 169 & 33.1 \\
\hline \multicolumn{3}{|l|}{ Need of training on $\mathrm{Pl}$ prevention } \\
\hline Yes & 486 & 95.3 \\
\hline No & 24 & 4.7 \\
\hline
\end{tabular}

Notes: $\mathrm{n}=$ frequency, $\%=$ percentage. "prevention of pressure injuries" (68.86 \pm 16.32$)$, and "classification and observation" (72.25 \pm 20.73$)$. The highest score was on the theme of "specific patient group," with an average score of $95.20 \pm 18.31$ (Table 2). Noticeably, $61.8 \%$ of participants reported that "side $90^{\circ}$ lateral position is more effective than side $30^{\circ}$ lateral position," and $31.2 \%$ of participants stated that the use of a ring cushion (donut) was effective to prevent PI. Overall, only $5.1 \%$ of participants showed sufficient PI prevention knowledge (Table 3).

\section{Pressure Injury Prevention Attitudes}

Mean score for PI prevention attitude was $76.65 \pm 8.62$ for all participants. The lowest mean score was found on the theme of "personal competence to prevent pressure injuries" (70.16 $\pm 11.51)$. Second-lowest mean score was on the theme of "confidence in the effectiveness of PI prevention" (75.74 \pm $12.95)$, followed by "priority of PI prevention" (77.83 \pm 11.79) and "impact of PI" (79.52 \pm 13.40$)$. The highest mean score was found in "responsibility in PI prevention" (81.23 \pm 13.41 ; Table 2). Overall, $54.50 \%$ of participants held positive attitudes toward PI prevention (Table 3).

\section{Pressure Injury Prevention Practices}

Mean score for self-reported PI prevention practices was $83.35 \pm 13.55$ for participants. On the sub-scales, the lowest mean score was found on the theme of "nutrition for PI prevention" (73.92 \pm 23.98$)$, followed by "use of risk instruments" (76.22 \pm 15.21$)$, "force and pressure redistribution" (82.22 \pm 18.48$)$, and "evaluation, skin care, and selection of special surfaces for pressure management" $(84.85 \pm 14.85)$. The highest mean score was found on the theme "postural change" (88.84 \pm 16.19 ; Table 2). On the whole, most participants $(68.80 \%)$ reported good PI prevention practices (Table 3).

\section{Differences in Pressure Injury Prevention} Knowledge, Attitude, and Practice Scores by Participants' Demographic

\section{Characteristics}

Table 4 shows that participants with higher educational levels $(P<0.01)$, from tertiary hospitals $(P<0.05)$, and with training experience on PI prevention during the previous year $(P<0.01)$ had higher PI prevention knowledge scores. However, there was no significant difference in PI prevention knowledge scores among participants who differed in age, gender, years worked in ICUs, and need for training on PI prevention (all $P>0.05$ ). 
Table 2 Mean Percentage Scores and Mean Sub-Scale Percentage Scores of Participants' Pressure Injury Prevention Knowledge, Attitudes, and Practices

\begin{tabular}{|c|c|c|c|c|}
\hline Scale & Sub-Scale & Min-Max & $M$ & $S D$ \\
\hline Knowledge & $\begin{array}{l}\text { Etiology } \\
\text { Classification and observation } \\
\text { Risk assessment } \\
\text { Nutrition for PI prevention } \\
\text { Prevention of pressure injuries } \\
\text { Special Patient Group }\end{array}$ & $27.27-100$ & $\begin{array}{l}65.82 \\
50.90 \\
72.25 \\
58.82 \\
61.11 \\
68.86 \\
95.20\end{array}$ & $\begin{array}{l}9.29 \\
15.26 \\
20.73 \\
32.12 \\
20.41 \\
16.32 \\
18.31\end{array}$ \\
\hline Attitude & $\begin{array}{l}\text { Personal competency to prevent } \mathrm{PI} \\
\text { Priority of } \mathrm{PI} \text { prevention } \\
\text { Impact of } \mathrm{PI} \\
\text { Responsibility of PI prevention } \\
\text { Confidence in the effectiveness of } \mathrm{PI} \text { prevention }\end{array}$ & $48.08-100$ & $\begin{array}{l}76.65 \\
70.16 \\
77.83 \\
79.52 \\
81.23 \\
75.74\end{array}$ & $\begin{array}{l}8.62 \\
11.51 \\
11.79 \\
13.40 \\
13.41 \\
12.95\end{array}$ \\
\hline Practices & $\begin{array}{l}\text { Use of risk predictive instruments } \\
\text { Evaluation, skin care, and the selection of special surface } \\
\text { Postural change } \\
\text { Force and pressure relief } \\
\text { Nutrition for PI prevention }\end{array}$ & $24.7 I-100$ & $\begin{array}{l}83.35 \\
76.22 \\
84.85 \\
88.84 \\
82.22 \\
73.92\end{array}$ & $\begin{array}{l}13.55 \\
15.21 \\
14.85 \\
16.19 \\
18.48 \\
23.98\end{array}$ \\
\hline
\end{tabular}

Abbreviations: M, mean; SD, standard deviation; Min, minimum; Max, maximum.

Participants who had received training on PI prevention over the last year had higher PI prevention attitude scores than those who had not $(P=0.001)$. We saw no significant difference in PI prevention attitude scores among participants who differed in age, gender, highest educational level, type of hospital, years worked in ICUs, and need for training on PI prevention (all $P>0.05$; Table 4).

Self-reported PI prevention practice scores did not significantly differ among participants of different ages, genders, highest educational levels, types of hospitals, years

Table 3 Frequency, Percentage, and Level of Participants' Pressure Injury Prevention Knowledge, Attitudes, and Practices

\begin{tabular}{|l|l|l|}
\hline Level & $\mathbf{n}$ & $\%$ \\
\hline Knowledge & & \\
$\quad$ Adequate $(\geq 80 \%)$ & 26 & 5.1 \\
Inadequate (<80\%) & 484 & 94.9 \\
\hline Attitudes & & \\
Positive ( $\geq 75 \%)$ & 278 & 54.5 \\
Negative (<75\%) & 232 & 45.5 \\
\hline Practice & & \\
Satisfactory $(\geq 80 \%)$ & 351 & 68.8 \\
Unsatisfactory (<80\%) & 159 & 31.2 \\
\hline
\end{tabular}

Notes: $\mathrm{n}=$ frequency, \% = percentage. worked in ICUs, training experience on PI prevention over the last year, and need for training on PI prevention (all $P>0.05)$.

\section{Discussion}

In this study, we investigated Chinese ICU nurses' PI prevention KAP levels. The results revealed that their knowledge of PI prevention was insufficient, their attitude toward PI prevention was acceptable, and their selfreported PI prevention practices were satisfactory.

\section{ICU Nurses' Knowledge of PI Prevention}

Our results implied that ICU nurses' knowledge of PI prevention was inadequate, with a mean score of 65.82 ; this finding was consistent with the results of previous studies. $^{20,25,28,38,39}$ Khojastehfar et $\mathrm{al}^{25}$ reported that a low level of PI prevention knowledge might be associated with a lack of in-service training programs. The present study revealed that $33.1 \%$ of participants had not received training on PI prevention over the last year, which might have been due to nurses' heavy workloads and lack of time to participate in training programs. Nursing managers should take note of this issue and establish strategies to increase ICU nurses' participation in PI training programs so as to improve their PI prevention 
Table 4 Comparison of Participants' Pressure Injury Prevention Knowledge, Attitudes, and Practices by Demographic Characteristics

\begin{tabular}{|c|c|c|c|c|c|c|c|c|c|}
\hline \multirow[t]{2}{*}{ Characteristics } & \multicolumn{3}{|c|}{ PI Prevention Knowledge } & \multicolumn{3}{|c|}{ PI Prevention Attitudes } & \multicolumn{3}{|c|}{ PI Prevention Practices } \\
\hline & $\begin{array}{l}M \pm S D \\
(M d \pm I Q R)\end{array}$ & Statistics & $p$ & $M \pm S D$ & Statistics & $p$ & $M \pm S D$ & Statistics & $p$ \\
\hline $\begin{array}{l}\text { Age } \\
21-30 \\
3 \mid-40 \\
4 \mid-50\end{array}$ & $\begin{array}{l}65.03^{\mathrm{a}} \pm 9.83^{\mathrm{b}} \\
66.55^{\mathrm{a}} \pm 8.56^{\mathrm{b}} \\
69.05^{\mathrm{a}} \pm 7.95^{\mathrm{b}}\end{array}$ & $2.94^{f}$ & 0.054 & $\begin{array}{l}76.17 \pm 8.49 \\
76.90 \pm 8.83 \\
80.59 \pm 7.37\end{array}$ & $2.74^{f}$ & 0.066 & $\begin{array}{l}83.23 \pm 13.94 \\
83.41 \pm 13.50 \\
84.48 \pm 8.05\end{array}$ & $0.09^{f}$ & 0.917 \\
\hline $\begin{array}{l}\text { Gender } \\
\text { Female } \\
\text { Male }\end{array}$ & $\begin{array}{l}65.53^{\mathrm{a}} \pm 9.42^{\mathrm{b}} \\
67.47^{\mathrm{a}} \pm 8.41^{\mathrm{b}}\end{array}$ & $-1.70^{e}$ & 0.090 & $\begin{array}{l}76.94 \pm 8.43 \\
75.05 \pm 9.51\end{array}$ & $1.77^{\mathrm{e}}$ & 0.077 & $\begin{array}{l}83.62 \pm 13.27 \\
81.85 \pm 15.03\end{array}$ & $1.06^{\mathrm{e}}$ & 0.291 \\
\hline $\begin{array}{l}\text { Final Education Level } \\
\text { Junior College } \\
\text { Bachelor and above }\end{array}$ & $\begin{array}{l}63.82^{\mathrm{a}} \pm 10.47^{\mathrm{b}} \\
66.65^{\mathrm{a}} \pm 8.66^{\mathrm{b}}\end{array}$ & $-3.13^{\mathrm{e}}$ & $0.002^{* *}$ & $\begin{array}{l}75.72 \pm 8.58 \\
77.05 \pm 8.64\end{array}$ & $-1.57^{\mathrm{e}}$ & 0.117 & $\begin{array}{l}83.17 \pm 14.38 \\
83.49 \pm 13.21\end{array}$ & $-0.24^{e}$ & 0.810 \\
\hline $\begin{array}{l}\text { Type of Hospital } \\
\text { Secondary } \\
\text { Tertiary }\end{array}$ & $\begin{array}{l}64.57^{\mathrm{a}} \pm 9.43^{\mathrm{b}} \\
66.48^{\mathrm{a}} \pm 9.17^{\mathrm{b}}\end{array}$ & $-2.22^{\mathrm{e}}$ & $0.027^{*}$ & $\begin{array}{l}75.72 \pm 8.25 \\
77.14 \pm 8.78\end{array}$ & $-1.77^{\mathrm{e}}$ & 0.077 & $\begin{array}{l}82.00 \pm 14.66 \\
84.06 \pm 12.89\end{array}$ & $-1.64^{e}$ & 0.102 \\
\hline $\begin{array}{l}\text { Working years in ICU } \\
\qquad 5 \\
5-10 \\
>10\end{array}$ & $\begin{array}{l}64.82^{\mathrm{a}} \pm 9.80^{\mathrm{b}} \\
66.75^{\mathrm{a}} \pm 8.66^{\mathrm{b}} \\
66.98^{\mathrm{a}} \pm 8.73^{\mathrm{b}}\end{array}$ & $2.98^{f}$ & 0.051 & $\begin{array}{l}76.30 \pm 8.19 \\
76.49 \pm 9.27 \\
78.29 \pm 8.29\end{array}$ & $1.54^{\mathrm{f}}$ & 0.216 & $\begin{array}{l}84.09 \pm 13.07 \\
82.19 \pm 14.35 \\
83.74 \pm 13.09\end{array}$ & $1.08^{f}$ & 0.339 \\
\hline $\begin{array}{l}\text { Received training over } \\
\text { the last year } \\
\text { Yes } \\
\text { No }\end{array}$ & $\begin{array}{l}68.18^{c} \pm 9.09^{d} \\
63.64^{c} \pm 13.64^{d}\end{array}$ & $24370.5^{g}$ & $0.004^{* *}$ & $\begin{array}{l}77.52 \pm 8.56 \\
74.91 \pm 8.50\end{array}$ & $3.24^{\mathrm{e}}$ & $0.00 I^{* *}$ & $\begin{array}{l}84.13 \pm 13.21 \\
81.78 \pm 14.12\end{array}$ & $1.85^{\mathrm{e}}$ & 0.065 \\
\hline $\begin{array}{l}\text { Need of Training } \\
\text { Yes } \\
\text { No }\end{array}$ & $\begin{array}{l}65.82^{\mathrm{a}} \pm 9.17^{\mathrm{b}} \\
65.91^{\mathrm{a}} \pm 11.76^{\mathrm{b}}\end{array}$ & $-0.05^{\mathrm{e}}$ & 0.962 & $\begin{array}{l}76.74 \pm 8.52 \\
74.84 \pm 10.55\end{array}$ & $1.06^{\mathrm{e}}$ & 0.292 & $\begin{array}{l}83.39 \pm 13.67 \\
82.60 \pm 10.94\end{array}$ & $0.28^{\mathrm{e}}$ & 0.780 \\
\hline
\end{tabular}

Notes: a Mean, ${ }^{b}$ standard deviation, ${ }^{c}$ median, ${ }^{d}$ interquartile range, ${ }^{e}$ Independent $t$-test, ${ }^{f}$ one-way analysis of variance, ${ }^{g}$ Mann-Whitney test, ${ }^{*} \mathrm{p}<0.05$, ${ }^{*} \mathrm{p}<0.01$. Abbreviations: M, mean; SD, standard deviation; Md, median; IQR, interquartile range.

knowledge. In addition, nursing administrators should consider the quality of training provided on PI prevention, such as whether course content has been updated with the latest scientific evidence. As this study showed, $31.2 \%$ of participants still believed that the use of a ring cushion was effective for preventing PI, and $61.8 \%$ reported that "side $90^{\circ}$ lateral position is more effective than side $30^{\circ}$ lateral position"; both practices are no longer recommended. ${ }^{3}$ Quite surprisingly, only 5.1\% of ICU nurses had adequate PI prevention knowledge. A study conducted among Chinese general nurses demonstrated that $58.3 \%$ had adequate PI prevention knowledge. ${ }^{31}$ This large discrepancy might be due to the different questionnaires and cutoff scores between that study and the current one. The earlier study applied the Pressure Ulcer Knowledge Test (PUKT) ${ }^{31}$ In the original questionnaire, $90 \%$ was recommended as a cutoff score, but in that study a mean score of $80 \%$ indicated that nurses' PI prevention knowledge was sufficient. ${ }^{31}$ In our study, we used PUKAT 2.0 and set $80 \%$ as a cutoff score for sufficient knowledge. However, one study using PUKAT showed that ICU nurses' PI prevention knowledge was only 52.5/100. ${ }^{26}$ Therefore, the high cutoff score that we selected might have resulted in most participants scoring as having insufficient PI prevention knowledge.

Our findings indicated that participants with bachelor's degrees had higher knowledge than those with juniorcollege certifications, which was in agreement with the findings of some previous studies. ${ }^{39-42}$ Furthermore, our results confirmed earlier findings that nurses who had received training on PI prevention had better knowledge than those who had not received such training. ${ }^{20,39,41,42}$ These findings highlighted the importance of continuing education or in-service training in PI prevention. We also found that nurses from tertiary hospitals had better knowledge than those from secondary hospitals. One reason 
might be that the former group has a higher level of medical education: $74.3 \%$ of our participants from tertiary hospitals held bachelor's or master's degrees, while only $65.9 \%$ of participants from secondary hospitals held bachelor's degrees. Another reason might be that tertiary hospitals have more-complete PI management systems than secondary hospitals, providing more-relevant training on PI for nurses and setting up wound care groups, which makes it easier for nurses to update their PI prevention knowledge.

\section{ICU Nurses' Attitudes Toward PI Prevention}

The present study demonstrated that ICU nurses' attitudes toward PI prevention were generally positive, with a mean score of 76.65. Studies conducted among ICU nurses from other countries have yielded similar findings. ${ }^{24,43}$ However, it should be noted that $45.5 \%$ of nurses in this study held negative attitudes toward PI prevention. Strategies to enhance ICU nurses' attitudes toward PI prevention are still necessary. In contrast with our findings, Khojastehfar et $\mathrm{al}^{25}$ reported that ICU nurses in Iran had undesirable attitudes toward PI prevention. The difference might be due to the response format of the questionnaire. Khojastehfar et $\mathrm{al}^{25}$ scored items on a 5-point Likert scale, while in the current study we used a 4-point Likert scale. Our participants' attitudes toward PI prevention differed by theme; the highest score corresponded with the theme of "responsibility in PI prevention," the lowest with that of "personal competence to prevent pressure injuries." These findings indicated that ICU nurses took a high level of responsibility for PI prevention but lacked competence and confidence to prevent PIs. This was consistent with the findings of Feng et $\mathrm{al}^{29}$ and Jiang et $\mathrm{al}^{31}{ }^{31}$ who stated that general nurses hold positive attitudes toward PI prevention but lack confidence and competence. Therefore, nursing administrators should develop programs strengthening ICU nurses' competence and confidence in PI prevention.

Participants in the current study who had received training on PI prevention over the last year had morepositive attitudes toward PI prevention. This might be because training on PI prevention can improve nurses' capability of to prevent PI, thereby reducing their confusion and increasing their confidence in PI prevention. The findings of Habiballah ${ }^{42}$ and Unver et $\mathrm{al}^{44}$ were similar in that nurses who had undergone training on PI prevention had better attitudes toward PI prevention. Therefore, to improve patient safety, nursing administrators should consider providing optimal training to nurses to help them gain competence and confidence in PI prevention so as to improve their attitudes. In line with previous studies, we found no statistically significant differences in attitudes among participants of different demographic characteristics such as age, ${ }^{45}$ gender, ${ }^{20,24}$ educational level, ${ }^{20,24,45}$ hospital type, ${ }^{42}$ and working experience in ICUs. ${ }^{20,24}$ Contrary to the current findings, Etafa et $\mathrm{al}^{45}$ reported that male nurses had more-positive attitudes toward PI prevention than female nurses, while Habiballah et $\mathrm{al}^{43}$ argued the converse.

\section{ICU Nurses' PI Prevention Practices}

We found ICU nurses' self-reported practices of PI prevention to be at a high level, with a mean score of 83.35. This was consistent with the study by Khojastehfar et al, ${ }^{25}$ who stated that Iranian ICU nurses' PI prevention practices were desirable. This finding in our study, coupled with the fact that $68.8 \%$ of participants had satisfactory PI prevention practices, indicated that the practice level of ICU nurses in this study was acceptable It is not surprising that our participants scored relatively high on PI prevention practices, because PI incidence has been established as a nursing-sensitive indicator that is incorporated into nursing quality management and hospital accreditation evaluation in China. Once a PI occurs, the department must report it to the nursing quality control and management department, which not only increases the workload of nurses but also affects the departmental evaluation. Therefore, external pressure to prevent PIs might force nurses to set it as a priority and to do well at such prevention. We found that Chinese general nurses' practices of PI prevention were also at a high level. ${ }^{31}$ This was in contrast with other studies conducted among ICU nurses in other countries. ${ }^{28,38}$ The majority of ICU nurses (two thirds) in Egypt showed unsatisfactory levels of practice in PI prevention and management; ${ }^{39}$ similarly, an earlier study reported that the PI prevention practices of ICU nurses in Nepal was unacceptable. ${ }^{28}$

Participants scored lowest on the theme of "nutrition." Similarly, Kim et al found that nurses exhibited relatively low performance in nutrition for PI prevention. ${ }^{46}$ Nutrition is considered important for preventing PIs in at-risk patients, ${ }^{4}$ but interdisciplinary-team cooperation is needed to achieve sufficient nutrition management, which might impede nurses' nutritional practices. Furthermore, the highest score was on the theme of "postural change." 
This preventive measure is easy for nurses to perform, as it does not require much time or special equipment but is one of the most effective ways to prevent PIs.

In the present study, we found no significant differences in practice score among nurses by demographic characteristics. Some previous studies have likewise found that educational level, ${ }^{27}$ work experience, ${ }^{27}$ and hospital type ${ }^{46}$ have no significant effect on nurses' PI prevention practices. However, in contrast with the current study, previous training on PI prevention is reported to have significantly affected nurses' PI prevention practices. $^{27,38,46}$ Because PI prevention knowledge is updated dynamically, the authors of those studies believe that regular training on PI prevention is necessary for nurses, even though our results showed that training experience had no effect on nurses' PI prevention practices. Another study reported that repeated training can improve nurses' practices over time and then maximize their ability to prevent PIs. ${ }^{31}$

In summary, the findings of this study revealed that inservice training or continuing education on PI prevention should be developed to improve ICU nurses' insufficient knowledge of PI prevention and to optimize their attitudes toward and practices of PI prevention.

\section{Limitations}

The present study had some limitations. We used the convenience sampling method to recruit participants, which might limit the generalization of the findings. The PUKAT 2.0 questionnaire was modified for this study, but we failed to calculate the intraclass correlation of each subscale. In addition, because the survey assessing ICU nurses' PI prevention knowledge was conducted online, participants might have searched the internet for the answers, which would have affected the results. Finally, the questionnaires used in the current study assessed nurses' self-reported PI prevention practices, which might have been different from their actual PI prevention practices. We recommend that a future observational study be conducted to explore the phenomenon of nurses' practices of PI prevention.

\section{Conclusions}

In conclusion, although ICU nurses' attitudes toward PI prevention were acceptable and their self-reported practices of PI prevention were satisfactory, their knowledge of PI prevention was insufficient, which might be a barrier to prevention of PIs. Considering that PIs are most prevalent in the ICU setting and that they have detrimental effects on patients, it is essential for nursing administrators to develop continuing education or in-service training programs to enhance nurses' knowledge of PI prevention. Moreover, we recommend that nursing administrators explore strategies to guarantee nurses' participation and to improve training quality in order to increase training effectiveness in the future.

\section{Funding}

Partial financial support was provided by the Graduate School of Prince of Songkla University in the form of a grant.

\section{Disclosure}

The authors declare no conflict of interest regarding this work.

\section{References}

1. Edsberg LE, Black JM, Goldberg M, McNichol L, Moore L, Sieggreen M. Revised national pressure ulcer advisory panel pressure injury staging system: revised pressure injury staging system. J Wound, Ostomy, Continence Nurs. 2016;43(6):585-597. doi:10.1097/WON.0000000000000281

2. Pickham D, Berte N, Pihulic M, Valdez A, Mayer B, Desai M. Effect of a wearable patient sensor on care delivery for preventing pressure injuries in acutely ill adults: a pragmatic randomized clinical trial (LS-HAPI study). Int J Nurs Stud. 2018;80:12-19. doi:10.1016/j. ijnurstu.2017.12.012

3. National Pressure Ulcer Advisory Panel, European Pressure Ulcer Advisory Panel, Pan Pacific Pressure Injury Alliance. Prevention and Treatment of Pressure Ulcers: Clinical Practice Guideline. Haesler E, ed. Perth, Australia: Cambrige Media; 2014.

4. European Pressure Ulcer Advisory Panel, National Pressure Injury Advisory Panel, and Pan Pacific Pressure Injury Alliance. Prevention and Treatment of Pressure Ulcers/Injuries: Clinical Practice Guideline. The International Guideline. 3rd ed. Haesler E, ed. 2019. http://internationalguideline.com. Accessed October 24, 2020.

5. Li Z, Lin F, Thalib L, Chaboyer W. Global prevalence and incidence of pressure injuries in hospitalised adult patients: a systematic review and meta-analysis. Int J Nurs Stud. 2020;105:103546. doi:10.1016/j. ijnurstu.2020.103546

6. Chaboyer WP, Thalib L, Harbeck EL, et al. Incidence and prevalence of pressure injuries in adult intensive care patients: a systematic review and meta-analysis. Crit Care Med. 2018;46(11):e1074-e1081. doi:10.1097/CCM.0000000000003366

7. Ahtiala MH, Soppi ET, Wiksten A, Koskela H, Grönlund JA. Occurrence of pressure ulcers and risk factors in a mixed MedicalSurgical ICU-a cohort study. J Intensive Care Soc. 2014;15 (4):340-343. doi:10.1177/175114371401500415

8. González-Méndez MI, Lima-Serrano M, Martín-Castaño C, AlonsoAraujo I, Lima-Rodríguez JS. Incidence and risk factors associated with the development of pressure ulcers in an intensive care unit. J Clin Nurs. 2018;27(5-6):1028-1037. doi:10.1111/jocn.14091

9. Serra R, Caroleo S, Buffone G, et al. Low serum albumin level as an independent risk factor for the onset of pressure ulcers in intensive care unit patients. Int Wound J. 2014;11(5):550-553. doi:10.1111/iwj.12004 
10. Zarei E, Madarshahian E, Nikkhah A, Khodakarim S. Incidence of pressure ulcers in intensive care units and direct costs of treatment: evidence from Iran. $J$ Tissue Viability. 2019;28(2):70-74. doi:10.1016/j.jtv.2019.02.001

11. Özyürek P, Yavuz M, Yıldız Ö. Investigation of the risk factors of pressure ulcers in intensive care unit patients: according to the Braden Scale. East J Med. 2016;21(1):1. doi:10.5505/ejm.2016.21939

12. El-Marsi J, Zein-El-Dine S, Zein B, Doumit R, Kurdahi Badr L. Predictors of pressure injuries in a critical care unit in Lebanon: prevalence, characteristics, and associated factors. $J$ Wound, Ostomy Continence Nurs. 2018;45 (2):131-136. doi:10.1097/WON.0000000000000415

13. Tayyib N, Coyer F, Lewis P. Saudi Arabian adult intensive care unit pressure ulcer incidence and risk factors: a prospective cohort study. Int Wound J. 2016;13(5):912-919. doi:10.1111/iwj.12406

14. Jiang Q, Li X, Qu X, et al. The incidence, risk factors and characteristics of pressure ulcers in hospitalized patients in China. Int $J$ Clin Exp Pathol. 2014;7(5):2587-2594.

15. Theisen S, Drabik A, Stock S. Pressure ulcers in older hospitalized patients and its impact on length of stay: a retrospective observational study. J Clin Nurs. 2012;21(3-4):380-387. doi:10.1111/j.1365-2702.2011.03915.x

16. Bauer K, Rock K, Nazzal M, Jones O, Qu W. Pressure ulcers in the United States' inpatient population from 2008 to 2012: results of a retrospective nationwide study. Ostomy Wound Manage. 2016;62(11):30-38.

17. Padula WV, Delarmente BA. The national cost of hospital-acquired pressure injuries in the United States. Int Wound J. 2019;16 (3):634-640. doi:10.1111/iwj.13071

18. Guest JF, Fuller GW, Vowden P, et al. Cohort study evaluating pressure ulcer management in clinical practice in the UK following initial presentation in the community: costs and outcomes. BMJ Open. 2018;8:e021769. doi:10.1136/bmjopen-2018-021769

19. Espejo E, Andrés M, Borrallo R, Padilla E, Garcia-Restoy E, Bella F. Bacteremia associated with pressure ulcers: a prospective cohort study. Eur J Clin Microbiol Infect Dis. 2018;37:969-975. doi:10.1007/s10096-018-3216-8

20. Tirgari B, Mirshekari L, Forouzi MA. Pressure injury prevention: knowledge and attitudes of Iranian intensive care nurses. Adv Skin Wound Care. 2018;31(4):1-8. doi:10.1097/01.ASW.0000530848.50085.ef

21. Rav-Marathe K, Wan T, Marathe SJMRA. A systematic review on the KAP-O framework for diabetes education and research. Med Res Arch. 2014;4(1):1-22.

22. Berihu H, Wubayehu T, Teklu T, Zeru T, Gerensea H. Practice on pressure ulcer prevention among nurses in selected public hospitals, Tigray, Ethiopia. BMC Res Notes. 2020;13(1):207. doi:10.1186/ s13104-020-05049-7

23. Barakat-Johnson M, Barnett C, Wand T, White K. Knowledge and attitudes of nurses toward pressure injury prevention: a cross-sectional multisite study. J Wound, Ostomy Continence Nurs. 2018;45(3):233-237. doi:10.1097/WON.0000000000000430

24. Tayyib N, Coyer F, Lewis P. Pressure injury prevention in a Saudi Arabian intensive care unit: registered nurse attitudes toward prevention strategies and perceived facilitators and barriers to evidence implementation. J Wound, Ostomy Continence Nurs. 2016;43 (4):369-374. doi:10.1097/WON.0000000000000245

25. Khojastehfar S, Najafi Ghezeljeh T, Haghani S. Factors related to knowledge, attitude, and practice of nurses in intensive care unit in the area of pressure ulcer prevention: a multicenter study. $J$ Tissue Viability. 2020;29(2):76-81. doi:10.1016/j.jtv.2020.02.002

26. De Meyer D, Verhaeghe S, Van Hecke A, Beeckman D. Knowledge of nurses and nursing assistants about pressure ulcer prevention: a survey in 16 Belgian hospitals using the PUKAT 2.0 tool. J Tissue Viability. 2019;28(2):59-69. doi:10.1016/j.jtv.2019.03.002

27. Lotfi M, Aghazadeh AM, Asgarpour H, Nobakht A. Iranian nurses' knowledge, attitude and behaviour on skin care, prevention and management of pressure injury: a descriptive cross-sectional study. Nurs Open. 2019;6(4):1600-1605. doi:10.1002/nop2.365
28. Shrestha A, Maneewat K, Kritpracha C. Nepalese critical care nurses' competency towards pressure ulcer prevention. GSTF J Nurs Health Care. 2017;5(1):e12.

29. Feng CC, Zhao SZ, Hu AL.Correlation of nurses' knowledge, attitude and behavior on pressure ulcer prevention. Chin J Mod Nurs. 2017;23(28):3623-3628.

30. Liu YT, Wu LQ, Wei XX.Investigation of junior nurses' knowledge, attitude and practice of pressure ulcer care and its related factors. Chin Gen Nurs Pract. 2016;14(10):986-988.

31. Jiang L, Li L, Lommel L. Nurses' knowledge, attitudes, and behaviours related to pressure injury prevention: a large-scale crosssectional survey in mainland China. J Clin Nurs. 2020;29(1718):3311-3324. doi:10.1111/jocn. 15358

32. Yamane T. Statistics: An Introduction Analysis. 3rd ed. New York: Harper \& Row; 1973.

33. Moya-Suárez AB, Canca-Sánchez JC, Enríquez DLRM, ArandaGallardo M, Morales-Asencio JM. Factors associated with variability in the prevention of pressure ulcers. J Tissue Viability. 2018;27 (4):211. doi:10.1016/j.jtv.2018.10.006

34. Manderlier B, Van Damme N, Vanderwee K, Verhaeghe S, Van Hecke A, Beeckman D. Development and psychometric validation of PUKAT 2.0, a knowledge assessment tool for pressure ulcer prevention. Int Wound $J$. 2017;14(6):1041-1051. doi:10.1111/iwj.12758

35. Beeckman D, Vanderwee K, Demarre L, Paquay L, Van Hecke A, Defloor T. Pressure ulcers: development and psychometric evaluation of the attitude towards pressure ulcer prevention instrument (APuP). Int J Nurs Stud. 2010;47(11):1432-1441. doi:10.1016/j.ijnurstu.2010.04.004

36. Polit DF, Beck CT. Nursing Research: Generating and Assessing Evidence for Nursing Practice. 10th ed. Philadephia, PA: Lippincott Williams \& Wilkins; 2017.

37. Kim HY. Statistical notes for clinical researchers: assessing normal distribution (2) using skewness and kurtosis. Restor Dent Endodont. 2013;38(1):52-54. doi:10.5395/rde.2013.38.1.52

38. Miller DM, Neelon L, Kish-Smith K, Whitney L, Burant CJ. Pressure injury knowledge in critical care nurses. $J$ Wound, Ostomy Continence Nurs. 2017;44(5):455-457. doi:10.1097/WON.0000000000000350

39. Taha AS. Nurses knowledge and practice related to pressure ulcer at intensive care unit. J Int Acad Res Multidiscip. 2014;2(2):247-262.

40. Köse I, Öztunç G. Knowledge of nurses working in intensive care units in relation to preventive interventions for pressure ulcer. Int J Caring Sci. 2016;9(2):677.

41. Beeckman D, Defloor T, Schoonhoven L, Vanderwee K. Knowledge and attitudes of nurses on pressure ulcer prevention: a cross-sectional multicenter study in Belgian hospitals. Worldviews Evidence-Based Nurs. 2011;8:166-176. doi:10.1111/j.1741-6787.2011.00217.x

42. Nuru N, Zewdu F, Amsalu S, Mehretie Y. Knowledge and practice of nurses toward pressure ulcer prevention in Gondar University Hospital, Northwest Ethiopia. BMC Nurs. 2015;14(1):34. doi:10.1186/s12912-015-0076-8

43. Habiballah L. Attitudes of intensive care nurses towards pressure ulcer prevention. Clin Nurs Stud. 2018;6(3):1. doi:10.5430/cns.v6n3p1

44. Ünver S, Fındık ÜY, Özkan ZK, Sürücü Ç. Attitudes of surgical nurses towards pressure ulcer prevention. $J$ Tissue Viability. 2017;26(4):277-281. doi:10.1016/j.jtv.2017.09.001

45. Etafa W, Argaw Z, Gemechu E, Melese B. Nurses' attitude and perceived barriers to pressure ulcer prevention. BMC Nurs. 2018;17:14. doi:10.1186/s12912-018-0282-2

46. Kim JK, Yoo SH, Nho JH, Ju JK. Performance and influencing factors of evidence-based pressure ulcer care among acute care hospital nurses. Worldviews Evidence-Based Nurs. 2019;16(1):29-35. doi:10.1111/wvn.12348 


\section{Publish your work in this journal}

Risk Management and Healthcare Policy is an international, peerreviewed, open access journal focusing on all aspects of public health, policy, and preventative measures to promote good health and improve morbidity and mortality in the population. The journal welcomes submitted papers covering original research, basic science, clinical \& epidemiological studies, reviews and evaluations, guidelines, expert opinion and commentary, case reports and extended reports. The manuscript management system is completely online and includes a very quick and fair peer-review system, which is all easy to use. Visit http://www.dovepress.com/testimonials.php to read real quotes from published authors.

Submit your manuscript here: https://www.dovepress.com/risk-management-and-healthcare-policy-journal 